\title{
Medications affecting glycemic control
}

\author{
Ghazwa B Korayem* \\ Pharmacy Practice Resident, College of Pharmacy, University of Arizona, Banner University Medical Center, Tucson, AZ, USA
}

\begin{abstract}
Introduction: Review non-diabetes management medications that are commonly associated with either serious hyper- or hypoglycemia, or both, outline their mechanisms, and provide strategies for limiting these undesirable glycemic effects.

Methods: Literature search of Pub-Med for studies in which drugs induced hyperglycemia or hypoglycemia. The primary outcome for this review was the incidence and occurrence of hyperglycemia and or hypoglycemia

Results: Both hyperglycemia and hypoglycemia are associated with negative outcomes. Blood glucose variation was significantly associated with mortality in nondiabetic greater than diabetic patients. Medications may contribute to this glycemic variation manifested as either hyperglycemia or hypoglycemia. Many medications have been associated with aggravating hyperglycemia in diabetes mellitus patients, causing new hyperglycemia or outright diabetes in previously non-diabetic individuals. Steroids, immunosuppressive agents, antipsychotics and many other medications are commonly associated with hyperglycemia. On the other hand, hypoglycemia is an uncommon adverse effect associated with some antimicrobials and other medications. The risk may be increased, however, when such medications are used concomitantly with anti-diabetic agents. Benefits of these medications associated with hyper- or hypoglycemia may offset the potential adverse effects of abnormal glycemic control making overall management of the patient a challenge.
\end{abstract}

Conclusion: Hyperglycemia, hypoglycemia, and glucose variation have been shown to contribute to negative outcomes. Therefore, it is imperative for clinicians to be aware of medications that may adversely affect glucose control. Withholding these medications may be justified in certain situations; however, any decision to avoid a medication based on glycemic effects must be carefully weighed against their benefit as well as the risks and benefits of alternative therapies.

\section{Introduction}

Hyperglycemia, hypoglycemia and blood glucose variability are associated with negative outcomes, including increased mortality in both individuals with or without diabetes mellitus (DM) [1-3]. Some medications alter glycemic hemostasis which manifests as either hyperglycemia or hypoglycemia [2]. Inconsistent caloric intake, stress, infections, organ failure, advanced age, intensive inpatient insulin regimens or inadequate glycemic therapy and polypharmacy also contribute to glucose alterations $[4,5]$. Therefore, controlling blood glucose (BG) in hospitalized or acutely ill patients is a challenge. Hormones involved in glucose hemostasis, such insulin, glucagon, catecholamines (CA), growth hormone, and cortisol, are also affected by some medications. This article aims to review non-DM medications medications that are commonly associated with either serious hyperor hypoglycemia, or both, and discusses their mechanisms, as well as providing strategies for limiting or avoiding the undesirable glycemic effects.

\section{Hyperglycemia}

Drug-induced diabetes is a global issue that is frequently overlooked. Medications can either aggravate diabetes-associated hyperglycemia, or may cause new hyperglycemia episodes or outright DM in previously non-DM individuals. The American Diabetes Association (ADA) classify drug induced DM under "monogenic diabetes syndromes," a specific type of DM that is drug- or chemical-induced [6]. Older age, high body mass index, or family history may increase the risk of medication induced hyperglycemia and impaired glucose tolerance (IGT) [5]. Regardless of the cause, the first step in managing patients with IGT, hyperglycemia or DM, should be preventing or mitigating modifiable risk factors through lifestyle modification including weight loss, maintaining a healthy diet, adequate physical activity and patient education. Clinical judgment along with continuous assessment of the patient's clinical status, illness severity, nutritional status, and concomitant medications potentially affecting glucose concentration should be incorporated into decisions to avoid, hold or continue therapy [7]. If DM develops, it may be appropriate to consider management with anti-diabetic agents.

\section{Atypical antipsychotic}

Second generation or atypical antipsychotics (AAP) are widely prescribed for the management of schizophrenia, other psychotic disorders and conditions with severe behavioral disturbance. Both typical antipsychotic (TAP) and AAP use may lead to metabolic abnormalities including hyperglycemia [8]. In addition, it should be recognized that schizophrenia itself may represent an inherent risk for developing type 2 DM [9]. Increased weight and concomitant use of valproic acid, selective serotonin reuptake inhibitors, or buspirone may also exacerbate hyperglycemia [10]. Antipsychotic-associated hyperglycemia occurs early in therapy but risk of new onset diabetes

Correspondence to: Ghazwa B Korayem, Pharmacy Practice Resident, College of Pharmacy, University of Arizona, Banner University Medical Center, Tucson, AZ , 0202, 1295 N, Martin Ave, AZ 85721, USA, Tel: +1(520)694-2265; E-mail: korayem@pharmacy.arizona.edu

Key words: hyperglycemia, hypoglycemia, medications, diabetes, steroids, glucose and insulin

Received: April 03, 2017; Accepted: May 01, 2017; Published: May 04, 2017 
mellitus (NODM) increases with chronic use $[8,11]$. AAP are associated with a higher risk of developing DM and more severe hyperglycemia compared to TAP [12]. AAP-associated hyperglycemia can be extreme and associated with ketoacidosis or hyperosmolar coma or death $[11,12]$. Therefore, in 2004 the Food and Drug Administration (FDA) issued a new warning on all APP drug labels regarding the increased risk of hyperglycemia and NODM [13]. Clozapine and olanzapine appear to have the highest risk and are also associated with a significantly higher risk of weight gain, impaired glycemic homeostasis and NODM $[14,15]$. Data on quetiapine is inconsistent; although minimal effect on glycemic control has been reported with ziprasidone, as well as aripiprazole [15-17] proposed mechanisms behind antipsychoticinduced DM, include drug-induced weight gain and insulin resistance. Potential mechanisms for weight gain include blocking serotonin $2 \mathrm{C}$ (5HT2C) or histamine $(\mathrm{H} 1)$ receptors, resulting in inhibited insulin secretion, insulin resistance, or impair glucose utilization $[18,19]$. Elevation of serum leptin or hyperprolactinemia may also induce insulin resistance $[18,19]$. In some cases, discontinuing the APP may resolve hyperglycemia; however, medication is generally required to prevent psychotic relapse and deterioration $[9,19]$. Both DM and schizophrenia are serious illnesses that require diligent management. Depending on patient and disease characteristics, it may be possible to substitute with a less diabetogenic APP. Fasting blood glucose (FBG) is recommended at baseline, 3 months, then annually for all patients, more frequently for those at higher risk of developing DM [20]. If patients develop hyperglycemia during treatment, injectable or oral anti-diabetic treatment may be initiated despite discontinuation of the suspect drug.

\section{Beta blockers ( $\beta B)$}

$\beta \mathrm{B}$ are commonly used for their cardiovascular benefits. However, Increasing FBG, NODM, and increasing hemoglobin A1c (A1C) have been linked to $\beta B$ use [21]. The overall magnitude of FBG increase appears to be minor $(0.6 \mathrm{mmol} / \mathrm{L}$ for pooled endpoint FBG) based on a meta-analysis of data from 1889 patients with DM [21]. Non-selective $\beta B$ had a greater effect than selective $\beta B(1.3 \mathrm{mmol} / \mathrm{L}$ and $0.15 \mathrm{mmol} / \mathrm{L}$ increases, respectively) in this meta-analysis although the literature as a whole is inconsistent [10,21-24]. Data are also inconsistent for NODM with $\beta B$ use. Reanalysis of the NAVIGATOR study data showed a non-significant increase in NODM; valsartan was used as the $\beta B$ and all participants met criteria for impaired glucose tolerance at study entry [25]. In contrast, a large meta-analysis evaluating NODM in participants without DM at randomization found an increased risk of NODM in patients prescribed $\beta B$ as initial therapy for hypertension [22]. The extent to which $\beta B$-associated glycemic effects may diminish the known cardiovascular benefits of $\beta \mathrm{B}$ is uncertain. Therefore, it is recommended to prescribe or continue $\beta B$ in DM patients as indicated while closely monitoring their BG and adjusting therapy for glucose management, if necessary [21].

\section{Epinephrine (EPI)}

EPI is a widely used vasopressor It contributes to stress-induced hyperglycemia and susceptibility of DM patients to the adverse metabolic effects [26,27]. When EPI is given as a drug, it acutely decreases insulin sensitivity and secretion, in individuals with or without DM $[28,29]$. The effect on glycogenolysis rapidly wanes; thus the EPI induced hyperglycemia is short lived. Notably, chronic use of EPI and other $\beta 2$ agonists improves cellular glucose uptake and metabolism [30]. EPI has contradictory roles. While it may raise blood glucose, in some circumstances, it is associated with lowering glucose
[26]. It is very difficult to isolate the causality on EPI as a vasopressor on glycemic control from other hyperglycemia contributing factors in critically ill patients. In patients who have stress- or EPI-induced hyperglycemia, it is more appropriate to manage the patient's glucose than avoiding or withholding essential vasopressor therapy.

\section{Niacin}

Nicotinic acid (niacin) is commonly used alone or in combination to increase high-density lipoprotein cholesterol and lower triglycerides. Deterioration of glucose tolerance, elevation of FBG concentrations and development of NODM have been reported with niacin use [31-33]. Birjmohun et al found the incidence of niacin-induced hyperglycemia to be around $2.3 \%$ in a meta-analysis including 30 trials with 4749 participants randomized to niacin or placebo [32]. Immediate release formulations showed the highest prevalence of hyperglycemia [33]. A review of consensus guidelines, published RCT, and non-RCT, concluded that increases in FBG are usually 4\%-5\% with niacin doses $\leq 2.5$ g daily, although increases may be greater in patients with DM [34]. Effects on A1c were nil to modest and reversible [33]. In contrast, another large meta-analysis with 26,340 non-diabetic participants followed for an average of 3.6 years found the risk of NODM was increased by $34 \%$ with niacin [35]. Niacin-associated hyperglycemia may develop due to modestly decreased insulin sensitivity [36,37]. Although doses of niacin currently used may result in minor deterioration of glycemic control in patients with DM; those patient may experience a dose-related increase in their glucose intolerance [38]. It is generally recommended to defer niacin therapy while attempting to improve glycemic control in patients with impaired FBG or IGT, and withdraw therapy or reduced dose in patients with niacin induced NODM [34]. The cardiovascular benefits of niacin may offset the potential adverse effects on glycemic control as shown in ADMIT study [33]. Niacin-induced NODM is an infrequent adverse drug effect that warrants niacin treatment withdrawal or dose reduction. Thus, niacin can be safely used in patients with DM while BG levels may be closely monitored during the first few months of use [33].

\section{Octreotide}

Octreotide, a somatostatin analogue, is used for numerous conditions because if its effects on gastrointestinal (GI) hormones and blood flow. The pharmacologic effects of octreotide on the counterregulatory hormones, insulin, glucagon, and growth hormone [39]. Resulting in hyperglycemia in $16 \%$ and hypoglycemia in $3 \%$ of treated patients with acromegaly, the only condition for which data are available [40]. Hyperglycemic effects can be mild or aggressive with overt DM developing through the inhibition of insulin release [41]. Due to direct effects on insulin secretion, octreotide may be useful for preventing rebound hypoglycemia in the management of sulfonylurea (SU) and dipeptidyl peptidase-4 (DPP-4) inhibitor overdoses [42,43]. Endocrine Society guidelines recommends monitoring bedside point of care (POC) glucose for at least 24 to $48 \mathrm{~h}$ after octreotide initiation, even in patients who were previously normoglycemic [44]. If POC levels are persistently above $7.7 \mathrm{mmol} / \mathrm{L}$, therapeutic intervention to reduce $B G$ should be considered [44].

\section{Pentamidine}

Most patients receiving pentamidine are immune-compromised and require treatment or prevention of Pneumocystis jiroveci (carinii) pneumonia (PJP). Intravenours and aerosolized pentamidine use has been associated altering glucose heamostasis [45]. Retrospective studies indicate $9 \%-32 \%$ of patients treated with pentamidine develop 
hyperglycemia; mean onset is approximately 52 days after initiating therapy [46]. Pentamidine induced hyperglycemia is attributed to either hyperamylasemia causing an increase in glucagon release or decreased insulin release, especially after a meal [47]. In vitro studies found that pentamidine induces irreversible $\beta$ cell damage, secretory defect and necrosis precipitating the development of DM [48-50]. Risk factors associated with hyperglycemia include higher cumulative or single pentamidine dose and renal impairment [46]. Dysglycemic effects of pentamidine can be delayed. Hyperglycemia and DM, with or without preceding hypoglycemia, can occur up to several months after cessation of therapy $[46,47]$. Therefore, patients should be educated on signs and symptoms of both hyper- and hypoglycemia, as well as their management and the importance of regular BG monitoring [47].

\section{Protease inhibitors (PIs)}

PIs are a critical component of the antiretroviral therapy for managing HIV and AIDS. However, many metabolic complications have been associated with PIs. The FDA issued a Public Health Advisory in 1997 describing post-marketing surveillance reports of NODM, exacerbation of preexisting DM, IGT and hyperglycemia in patients receiving PIs [57]. The incidence of hyperglycemia ranges between less than $1 \%$ to $6 \%$ and occurs as early as two weeks after initiation of PI therapy [52,53]. Overt DM was reported in $6 \%$ to $13 \%$, most commonly with indinavir, and was more frequently detected later in therapy [51-54]. Ritonavir and saquinavir, or concomitant medications affecting glucose control, such as GC or pentamidine, increase the risk of DM [52,55]. PIs induce IGT by either induction of peripheral insulin resistance or by reduction of $\beta$-cell function [53]. Although, metabolic adverse effects of PIs may not be serious enough to warrant discontinuation and may be resolved on discontinuation [56]. The International AIDS Society-USA Panel and the Panel on Antiretroviral Guidelines suggest avoiding PI-based regimens as initial therapy in patients with a concern of metabolic toxicity, preexisting abnormalities of glucose metabolism or with the first-degree relative with DM [55,57]. When a PI-based regimen cannot be avoided, routine monitoring of glucose and A1C is appropriate. Treatment with insulin or oral anti-diabetic agents should be considered if DM develops.

\section{Statins}

HMG-CoA reductase inhibitors, commonly referred to as 'statins', are widely used in the primary and secondary prevention of cardiovascular diseases to lower serum cholesterol. Mixed results have been reported for effects of statins on glucose control; however, in 2012 the FDA requested a safety label change on all statins to include risk of increased A1C and FBG concentrations [58]. Data supporting this statement showed a 5-25\% increased risk of NODM or DM treatment in patients receiving statin $[59,60]$. However, a recent cohort study showed no increase in NODM with statins [61]. Onset of initiating DM treatment or NODM reported as early as 6 months up to years after starting statin $[61,62]$. The risk of DM may increase with statin dose, intensity and is greater in individuals with pre-existing metabolic syndrome or prediabetes [61-63]. An observational study evaluating the effect of statins on FBG over a 2 year follow up period reported a statin-associated increase of $0.5 \mathrm{mmol} / \mathrm{L}$ in patients with $\mathrm{DM}$ and 0.2 $\mathrm{mmol} / \mathrm{L}$ without DM [63]. The precise mechanism(s) for statin-induced DM remains unclear, although hypotheses include statin induced insulin resistance, inhibited $\beta$ cell insulin secretion and synthesis, and decreased insulin-mediated cellular glucose uptake [64-66]. Based on current literature, the long-term CVD benefit of statins outweigh the risk of DM. Therefore, withholding statins in those at high risk of CVD is not recommended for the relatively minor concern of progression to DM [64].

\section{Thiazide}

Thiazide diuretics are indicated as adjunctive therapy in congestive heart failure-associated edema and hypertension. However, they have been linked to IGT, hyperglycemia more than NODM [61-69]. Hydrochlorothiazide or chlorthalidone have been reported to cause hyperglycemia more often than other diuretics, and a higher incidence of NODM was reported with chlorthalidone in the ALLHAT trial after 2 and 4 years follow-up [68]. The exact mechanism of thiazide-induced hyperglycemia remains unclear. One of the proposed mechanisms is through thiazide-induced hypokalemia, resulting in decreased insulin secretion and/or reduced insulin sensitivity $[67,70]$. On the other hand, a subgroup analysis of the PEAR study found no correlation between thiazide-induced changes in potassium and FBG levels [71]. Restoration of normoglycemia has been observed after thiazide discontinuation [72]. Nonetheless, avoiding or holding diuretics in patients with DM or hyperglycemia may be inappropriate since thiazide is usually necessary to provide symptomatic relief or achieve cardiovascular goals. Starting with a low dose and optimizing serum potassium concentrations is recommended when initiating thiazide in patients with DM [73].

\section{Transplant-associated hyperglycemia}

Medications for post-transplant immunosuppression (IS) account for $74 \%$ of new onset diabetes after transplant (NODAT); Glucocorticoids (GC) are the major cause [74]. Calcineurin inhibitors (CNI) are also implicated. Other NODAT risk factors include hypomagnesemia, which may decrease insulin sensitivity, and hepatitis $\mathrm{C}$ infection recipients [75]. Worsening of hyperglycemia in individuals with known pretransplant DM and hyperglycemia without pre-existing DM have been reported within the first 72 hours after transplant [76,77]. NODAT shares many similarities with type $2 \mathrm{DM}$ but in some cases may be reversible $[78,79]$. $\beta$-cell dysfunction is thought to be the main factor in the pathogenesis of NODAT $[80,81]$.

\section{Calcineurin inhibitors (CNI)}

Cyclosporine (CsA) and tacrolimus (Tac) remain a cornerstone of maintenance IS after transplant impaired glucose metabolism remains an issue associated with CNI-containing regimens despite the GC reduction allowed by CNI [78]. Toxic effects of CNI on the pancreas may contribute to insulin resistance and reduction in insulin secretion [82].

DIRECT study results indicate a significantly lower risk of NODAT with CsA regimens versus Tac in the first six months posttransplant [83]. Risk of NODAT increases with Tac trough concentrations $>15 \mathrm{ng} / \mathrm{mL}$ during the first month after transplantation [84]. Tac's profound diabetogenic effect may be due to Tac specific binding to FKBP-12 which is preferentially located in $\beta$-cells, resulting in Tac concentrating there [85]. CsA specifically binds to cyclophilin which is preferentially located in the heart, liver and kidneys [85]. Reducing the target for Tac trough concentrations below $10 \mathrm{ng} / \mathrm{ml}$,Tac dose, or switching from Tac to CsA may lower the incidence of NODAT or be effective in managing NODAT $[84,86]$. Conversely, reducing GC doses or switching from Tac to sirolimus (Sir) does not appear to improve glycemic control; insulin resistance may even worsen with Sir $[87,88]$. Sir itself impairs pancreatic $\beta$-cells responses and insulin production $[89,90]$. Ability to reduce IS doses or modifying IS regimen is often limited by other side effects of these medications and the risk of acute 
organ rejection [78]. All transplant patients need ongoing monitoring of FBG and periodic evaluation of A1C throughout the post-transplant period [86,89]. Management of patients with NODAT should follow a step-wise approach, similar to that followed for patients with type 2 DM [89].

\section{Glucocorticoids (GC)}

GC are widely prescribed for their significant anti-inflammatory and IS benefits. However, they are associated with hyperglycemia in individuals with or without DM and with development of NODM [8891]. Hyperglycemia may occur within 24 hours of receiving greater than physiologic doses, which is more than $10 \mathrm{mg}$ of prednisone daily or equivalent [90,92]. The risk of glucocorticoids induced hyperglycemia (GIH) varies depending on GC duration of therapy, potency, dose, route of administration [93,94]. An intermediate duration GC administered once daily will predominantly cause post-prandial hyperglycemia with a gradual decline toward normal overnight $[88,91]$. BG is more likely to be high throughout the day with multiple GC doses per day [91]. Increased insulin resistance occurs with GC-induced DM, similar to type 2 DM [88]. GCs antagonize the metabolic effects of insulin, particularly in the postprandial state through effects on reduced postprandial insulin secretion, promoting gluconeogenesis, increasing lipolysis and enhancing the effects of counter-regulatory hormones [9496]. GC may also cause $\beta$ cell dysfunction affecting insulin sensitivity and release. The treatment of choice for GC-induced hyperglycemia will vary depending on the GC used, frequency, duration of action, duration of therapy and current anti-diabetic regimen, if any (Table 1). Basal-bolus insulin (BBI) may be initiated with either neutral protamine Hagedorn $(\mathrm{NPH})$ or glargine insulin for hospitalized patients on GC with persistent hyperglycemia above or equal 11.1 $\mathrm{mmol} / \mathrm{L}[7,97]$. Both types of insulin have been shown to be are equally effective in small retrospective studies [7,97]. Any of 3 approaches are acceptable for insulin dosing: weight based insulin regimen, steroid dose based regimen or focused prandial insulin therapy [88]. Oral antidiabetic agents may be considered for outpatient management, when hyperglycemia is mild, or for short-term GC use [81]. Unfortunately, the risk of hypoglycemia may increase with most oral agents due to their slow onset and prolonged duration of action, as well as lack of selectively for postprandial hyperglycemia [81]. Shorter acting agents might be more appropriate, but exenatide is the only agent studied for GIH (Table 2) [88]. Exenatide targets postprandial hyperglycemia and has been shown to prevent prednisone induced glucose intolerance [98].

\section{Hypoglycemia}

Severe hypoglycemia has been associated with increased risk of adverse events including mortality and prolonged hospitalizations $[99,100]$. Several medications have been reported to increase the risk of hypoglycemia. Most commonly reported offending agents included trimethoprim-sulfamethoxazole, $\beta \mathrm{B}$, quinolones, pentamidine, quinine, angiotensin- converting enzyme inhibitors (ACEI), angiotension receptor blockers (ARB) and insulin-like growth factor [101,102]. However, A systematic review showed that stronger evidence supported the associations between quinolones, quinine, pentamidine and hypoglycemia as discussed below [101]. Certain anti-diabetic agents are at higher risk of hypoglycemia when used as monotherapy compared to other classes. Patients with renal dysfunction, liver disease, malnutrition, or advanced age are particularly at higher risk of medication-induced hypoglycemia [103,104]. Although medication induced hypoglycemia may be uncommon, precautions are necessary because failure to recognize hypoglycemia can be fatal. A standardized hospital-wide and nurse-initiated hypoglycemia treatment protocol should be in place to address hypoglycemia [2].

\section{Fluoroquinolones (FQ)}

FQ are frequently prescribed antibiotics. Increased use of these drugs has raised concern regarding rare but severe dysglycemia that may be fatal $[105,106]$. FQs have higher rates of both hyperglycemia and hypoglycemia compared to macrolides [107]. Higher risk of hypoglycemia was noted in patients concomitantly receiving antidiabetic agents in a nationwide cohort study [107]. Hypoglycemia has also been reported in patients without DM or not on hypoglycemic medication. Episodes occurred mostly at the beginning of FQ therapy and most occur after several days [108,109]. Moxifloxacin has been associated with the highest risk of hypoglycemia, followed by levofloxacin and ciprofloxacin [107]. FQ may cause hypoglycemia by increasing the release of insulin via a blockade of ATP-sensitive $\mathrm{K}+$ channels in a dose-dependent manner and FQ itself may enhance the glucose-induced insulin secretion [110]. Therefore, careful monitoring of blood glucose is recommended when FQ are used, especially if coadministered with anti-diabetic agents.

Table 1. Properties, dosing equivalents, effect on glucose and suggested insulin regimens of systemic corticosteroids.

\begin{tabular}{|c|c|c|c|c|c|c|}
\hline Glucocorticoids & $\begin{array}{l}\text { Equivalent dose } \\
\text { (mg) }\end{array}$ & $\begin{array}{l}\text { Relative glucocorticoid } \\
\text { activity }\end{array}$ & $\begin{array}{l}\text { Peak action } \\
\text { (hr) }\end{array}$ & $\begin{array}{l}\text { Duration of } \\
\text { action (hr) }\end{array}$ & Effect on glucose & Initial insulin regimen options \\
\hline \multicolumn{7}{|l|}{ Short Acting } \\
\hline Hydrocortisone & 20 & 1 & $1-4$ & $8-12$ & \multirow{2}{*}{$\begin{array}{l}\text { Short episodes of hyperglycemia } \\
\& \text { associated with higher } \\
\text { glycemic variability [99]. }\end{array}$} & \multirow{2}{*}{$\begin{array}{l}\text { Basal-bolus insulin } 0.3 \text { to } 0.5 \text { Units } / \mathrm{kg} \text { per day } \\
\text { [45]. }\end{array}$} \\
\hline Cortisone & 25 & 0.8 & $1-4$ & $8-12$ & & \\
\hline \multicolumn{7}{|l|}{ Intermediate Acting } \\
\hline Prednisone & 5 & 4 & $4-6$ & $12-36$ & \multirow{4}{*}{$\begin{array}{l}\text { Single dose: hyperglycemia } \\
\text { during the afternoon and night } \\
\text { without effect in fasting glucose } \\
\text { [89,100]. Divided doses: } \\
\text { persistent hyperglycemia }\end{array}$} & \multirow{4}{*}{$\begin{array}{l}\text {-Basal-bolus insulin } 0.3 \text { to } 0.5 \text { Units/kg per day [45]. } \\
\text {-Once daily oral regimen dose; NPH once daily at } \\
\text { the time of steroid dose [97,101]; NPH } 0.5 \text { units/ } \\
\text { mg glucocorticoid (range } 0.25-1.0 \text { units) daily } \\
\text { administered at the time of the GC dose [7] } \\
\text {-Twice or more dosing: NPH twice a day [101]; } \\
\text { NPH } 0.5 \text { units/mg GC (range } 0.25-1.0 \text { units) in } \\
\text { divided doses twice daily [7] }\end{array}$} \\
\hline Prednisolone & 5 & 4 & $4-6$ & $12-36$ & & \\
\hline Methylprednisolone & 4 & 5 & $4-6$ & $12-36$ & & \\
\hline Triamcinolone & 4 & 5 & $4-6$ & $12-36$ & & \\
\hline \multicolumn{7}{|l|}{ Long Acting } \\
\hline Dexamethasone & 0.75 & 30 & $1-2$ & $36-72$ & \multirow{2}{*}{$\begin{array}{l}\text { Hyperglycemia that lasts }>24 \mathrm{~h} \text {, } \\
\text { with a slight decline during an } \\
\text { overnight fast [81]. } \\
\text { insulin, hr: hours }\end{array}$} & \multirow[b]{2}{*}{$\begin{array}{l}\text {-Basal-bolus regimen using long acting insulin } \\
\text { [97,101] } \\
\text {-In patients already on BBI regimen; use } 140 \text { - } \\
150 \% \text { of BBI [7] } \\
\text {-Start NPH } 3 \text { units/mg of dexamethasone or } \\
\text { equivalent in divided doses twice daily [7] }\end{array}$} \\
\hline Table adapted but mod & ified from Liu D et & al., 2013 [138]; Furst et al. & 2012 [139]. BBI: & : Basal-Bolus & & \\
\hline
\end{tabular}




\begin{tabular}{|c|c|c|c|c|c|c|c|c|c|}
\hline Medications & Class effect & IGT & Hyperglycemia/FBG & NODM & Increase A1C & Time to occur & $\begin{array}{l}\text { May be reversible on } \\
\text { dis-continuation }\end{array}$ & Hypo-glycemia & Time to occur \\
\hline AAP & No $[8]$ & Yes [8] & Yes [12] & Yes [8] & Yes $[8,10]$ & late [8-10] & Yes $[9,18]$ & No & NA \\
\hline$\beta$-blockers & No§ [20] & Yes [17] & Yes [20] & Yes [21] & Yes [20] & Late [68] & - & Yes / $[29,30]$ & \\
\hline CNI & Yes [78] & Yes [77] & Yes [77] & Yes [78] & Yes $[76,123]^{*}$ & Early \& late & Yes [75] & No & NA \\
\hline Epinephrine & - & Yes [28] & Yes [28] & No [28] & - & Early [28] & Yes & No & NA \\
\hline FQ & Yes & - & Yes [116] & - & - & Late: days [117] & Yes & Yes [115] & Early [117] \\
\hline Niacin & - & Yes [31] & Yes [31] & Yes [31] & No [38] & $\begin{array}{l}\text { Late; weeks- months } \\
\text { [36] }\end{array}$ & Yes [34] & No & NA \\
\hline Octreotide & - & Yes [130] & Yes $[39,40]$ & Yes $[39,40]$ & - & Late $[39,40]$ & - & Yes [39] & Early \\
\hline Pentamidine & - & Yes [47] & Yes [47] & Yes [47] & - & Late [47] & No & Yes [120] & Early \\
\hline PI & Yes $[53]^{\top}$ & Yes [51] & Yes [51] & Yes [51] & Yes [124] & Late & Yes [56] & No & NA \\
\hline Steroids & Yes $[89,90]$ & Yes $[89,90]$ & Yes $[89,90]$ & Yes $[89,90]$ & Yes $[80,90]$ & Early & Yes & No & NA \\
\hline Statins & Yes $[61] \infty$ & Yes [64] & Yes [63] & Yes $[60,61]$ & Yes [63] & Late [63] & - & No & NA \\
\hline Thiazide & Yes [67] & Yes [67] & Yes [67] & Yes [67] & Yes [72] & Late [67] & Yes [72] & No & $\mathrm{NA}$ \\
\hline
\end{tabular}

AAP: Atypical antipsychotics, CNI: Calcinueurin inhibitors, FBG: Fasting blood glucose, FQ: Fluroquinolones, IGT:Impaired glucose tolerance,NODM: new onset diabetes mellitus, PI: Protease inhibitors. Late: $>14$ days of initiation, *NODAT not specifically CNI induced, §: Studies suggested that some non-selective vasodilating $\beta$ B may have favorable effects on glycemic control, but another meta analysis reported that the effect of non-selective $\beta B$ on FBG significantly more than those of selective $\beta B$ [20-24], /: $\beta B$ themselves do not induce hypoglycemia, but mostly mask hypoglycemia or delay hypoglycemia recovery. $\uparrow$ : Risk is higher with indinavir, sequinavir and ritonavir [51-55], $\infty$ : Risk is higher with high-intensity statins [61-63], - : No date, NA: None Applicable.

\section{Pentamidine}

Both hypoglycemia and hyperglycemia have been observed with pentamidine. Hypoglycemia occurs in $7 \%-38 \%$ of patients receiving pentamidine, either parentally or inhaled [45,111]. Onset of hypoglycemia may appear within hours to days after the first dose [47]. Early, sudden, sever and fatal hypoglycemia preceding hyperglycemia has also been reported [47,112]. Hypoglycemia may be attributed to an early excessive insulin leakage from $\beta$-cells and the absence or poor response of $\beta$-cells to glucagon [46]. Pentamidine induced nephrotoxicity and kidney dysfunction may prolong insulin action and contribute to hypoglycemia [47]. Patients should be educated about signs and symptoms of hypoglycemia and frequently monitor BG while on therapy.

\section{Quinines}

Parenteral quinine is no longer commercially available in the U.S [113]. Both quinine and quinidine including hydroxychloroquine may cause or aggravate hypoglycemia by stimulating insulin secretion, but quinine's effect is more potent $[113,114]$.

\section{Conclusion}

Hyperglycemia, hypoglycemia and glucose variation contribute to negative outcomes in DM and non-DM patients. Medications may play a significant role in glucose hemostasis with multiple mechanisms potentially contributing to dysglycemia. Knowing the mechanism(s) by which a medication induces hyperglycemia or hypoglycemia could help guide therapy and determine if the clinical benefit of the medication outweighs dysglycemic risks. Medications that pose higher risk of hyperglycemia or hypoglycemia may be avoided when therapeutic alternative exist while highly beneficial medications are appropriately selected despite their effect on glucose homeostasis.

\section{References}

1. Clement S, Braithwaite SS, Magee MF, Ahmann A, Smith EP, et al. (2004) Management of diabetes and hyperglycemia in hospitals. Diabetes Care 27: 553-591. [Crossref]

2. Moghissi ES, Korytkowski MT, DiNardo M, Einhorn D, Hellman R, et al. (2009) American Association of Clinical Endocrinologists and American Diabetes Association consensus statement on inpatient glycemic control. Diabetes care 32: 1119-1131. [Crossref]
3. Lanspa MJ, Dickerson J, Morris AH, Orme JF, Holmen J, et al. (2014) Coefficient of glucose variation is independently associated with mortality in critically ill patients receiving intravenous insulin. Crit Care 18: 86. [Crossref]

4. Magaji V, Johnston JM (2011) Inpatient management of hyperglycemia and diabetes. Clinical Diabetes 29: 3-9.

5. Gosmanov AR (2016) A practical and evidence-based approach to management of inpatient diabetes in non-critically ill patients and special clinical populations. $J$ Clin Transl Endocrinol 5: 1-6.

6. American Diabetes Association (2017) Standards of Medical Care in Diabetes-2017: Summary of Revisions. Diabetes Care 40: 123-124. [Crossref]

7. Wang CC, Draznin B (2013) Insulin use in hospitalized patients with diabetes: navigate with care. Diabetes Spectrum 26: 124-130.

8. Gianfrancesco FD, Grogg AL, Mahmoud RA, Wang RH, Nasrallah HA (2002) Differential effects of risperidone, olanzapine, clozapine, and conventional antipsychotics on type 2 diabetes: findings from a large health plan database. J Clin Psychiatry 63: 920-930. [Crossref]

9. Mukherjee S, Decina P, Bocola V, Saraceni F, Scapicchio PL (1996) Diabetes mellitus in schizophrenic patients. Compr Psychiatry 37: 68-73. [Crossref]

10. [Crossref] Bakris GL1, Fonseca V, Katholi RE, McGill JB, Messerli FH, et al. (2004) Metabolic effects of carvedilol vs metoprolol in patients with type 2 diabetes mellitus and hypertension: a randomized controlled trial. JAMA 292: 2227-2236.

11. Lindenmayer JP, Czobor P, Volavka J, Citrome L, Sheitman B, et al. (2003) Change in glucose and cholesterol levels in patients with schizophrenia treated with typical or atypical antipsychotics. Am J Psychiatr 160: 290-296. [Crossref]

12. Haupt DW, Newcomer JW (2001) Hyperglycemia and antipsychotic medications. $J$ Clin Psychiatry 62 Suppl 27: 15-26. [Crossref]

13. https://www.fda.gov/S afety/MedWatch/S a fety Information/ SafetyAlertsforHumanMedicalProducts/ucm166518.htm

14. Buse JB, Cavazzoni P, Hornbuckle K, Hutchins D, Breier A, et al. (2003) A retrospective cohort study of diabetes mellitus and antipsychotic treatment in the United States. $J$ Clin Epidemiol 56: 164-170. [Crossref]

15. Koro CE, Fedder DO, Gilbert JL, Weiss S, Magder L, et al. (2002) Assessment of independent effect of olanzapine and risperidone on risk of diabetes among patients with schizophrenia: population based nested case-control study. BMJ 325: 243. [Crossref]

16. Sobel M, Jaggers ED, Franz MA (1999) New-onset diabetes mellitus associated with the initiation of quetiapine treatment. J Clin Psychiatry 60: 556-557. [Crossref]

17. Simpson GM, Glick ID, Weiden PJ, Romano SJ, Siu CO (2004) Randomized, controlled, double-blind multicenter comparison of the efficacy and tolerability of ziprasidone and olanzapine in acutely ill inpatients with schizophrenia or schizoaffective disorder. Am J Psychiatry 161: 1837-1847. [Crossref] 
18. Brömel T, Blum WF, Ziegler A, Schulz E, Bender M, et al. (1998) Serum leptin levels increase rapidly after initiation of clozapine therapy. Mol Psychiatry 3: 76-80. [Crossref]

19. Lean ME, Pajonk FG (2003) Patients on atypical antipsychotic drugs: another high-risk group for type 2 diabetes. Diabetes Care 26: 1597-1605. [Crossref]

20. American Diabetes Association (2004) Consensus development conference on antipsychotic drugs and obesity and diabetes. Diabetes care 27: 596-601. [Crossref]

21. Hirst JA, Farmer AJ, Feakins BG, Aronson JK, Stevens RJ (2015) Quantifying the effects of diuretics and $B$-adrenoceptor blockers on glycaemic control in diabetes mellitus-a systematic review and meta-analysis. Br J Clin Pharmacol 79: 733-743. [Crossref]

22. Elliott WJ, Meyer PM (2007) Incident diabetes in clinical trials of antihypertensive drugs: a network meta-analysis. Lancet 369: 201-207. [Crossref]

23. Jacob S, Rett K, Wicklmayr M, Agrawal B, Augustin HJ, et al. (1996) Differential effect of chronic treatment with two beta-blocking agents on insulin sensitivity: the carvedilol-metoprolol study. J Hypertens 14: 489-494. [Crossref]

24. Fonseca VA (2010) Effects of beta-blockers on glucose and lipid metabolism. Curr Med Res Opin 26: 615-629. [Crossref]

25. Shen L, Shah BR, Reyes EM, Thomas L, Wojdyla D, et al. (2013) Role of diuretics, $B$ blockers, and statins in increasing the risk of diabetes in patients with impaired glucose tolerance: reanalysis of data from the NAVIGATOR study. BMJ 347: 6745. [Crossref]

26. Ebert SN, Rong Q, Boe S, Thompson RP, Grinberg A, et al. (2004) Targeted insertion of the Cre-recombinase gene at the phenylethanolamine n-methyltransferase locus: a new model for studying the developmental distribution of adrenergic cells. Dev Dyn 231: 849-858.[Crossref]

27. Dellinger RP, Levy MM, Rhodes A, Annane D, Gerlach H, et al. (2013) Surviving Sepsis Campaign: international guidelines for management of severe sepsis and septic shock, 2012. Crit Care Med 39: 165-228. [Crossref]

28. Marangou AG1, Alford FP, Ward G, Liskaser F, Aitken PM, et al. (1988) Hormona effects of norepinephrine on acute glucose disposal in humans: a minimal model analysis. Metabolism 37: 885-891. [Crossref]

29. Khoury N, McGill JB (2013) Reduction in insulin sensitivity following administration of the clinically used low-dose pressor, norepinephrine. Diabetes Metab Res Rev 27: 604-608. [Crossref]

30. Ziegler MG, Elayan H, Milic M, Sun P, Gharaibeh M (2012) Epinephrine and the metabolic syndrome. Curr Hypertens Rep 14: 1-7. [Crossref]

31. Birjmohun RS, Hutten BA, Kastelein JJ, Stroes ES (2005) Efficacy and safety of highdensity lipoprotein cholesterol-increasing compounds: a meta-analysis of randomized controlled trials. J Am Coll Cardiol 45: 185-197. [Crossref]

32. (1975) Clofibrate and niacin in coronary heart disease. JAMA 231: 360-381. [Crossref]

33. Elam MB, Hunninghake DB, Davis KB, Garg R, Johnson C, et al. (2000) Effect of niacin on lipid and lipoprotein levels and glycemic control in patients with diabetes and peripheral arterial disease: the ADMIT study: a randomized trial. JAMA 284: 12631270. [Crossref]

34. Guyton JR, Bays HE (2007) Safety considerations with niacin therapy. Am J Cardiol 99: 22C-31C. [Crossref]

35. Goldie C, Taylor AJ, Nguyen P, McCoy C, Zhao XQ, et al. (2016) Niacin therapy and the risk of new-onset diabetes: a meta-analysis of randomised controlled trials. Heart 102: 198-203. [Crossref]

36. Kelly JJ, Lawson JA, Campbell LV, Storlien LH, Jenkins AB, et al. (2000) Effects of nicotinic acid on insulin sensitivity and blood pressure in healthy subjects. J Hum Hypertens 14: 567. [Crossref]

37. Chang AM, Smith MJ, Galecki AT, Bloem CJ, Halter JB (2006) Impaired B-cell function in human aging: response to nicotinic acid-induced insulin resistance. $J$ Clin Endocrinol Meta 91: 3303-3309. [Crossref]

38. Gibbons LW, Gonzalez V, Gordon N, Grundy S (1995) The prevalence of side effects with regular and sustained-release nicotinic acid. Am J Med 99: 378-385. [Crossref]

39. Katz MD, Erstad BL (1989) Octreotide, a new somatostatin analogue. Clin Pharm 8: 255-273. [Crossref]

40. https://www.pharma.us.novartis.com/sites/www.pharma.us.novartis.com/files/ sandostatin_inj.pdf

41. Krentz AJ, Boyle PJ, Justice KM, Wright AD, Schade DS (1993) Successful treatment of severe refractory sulfonylurea-induced hypoglycemia with octreotide. Diabetes Care 16: 184-186. [Crossref]

42. Green RS1, Palatnick W (2003) Effectiveness of octreotide in a case of refractory sulfonylurea-induced hypoglycemia. J Emerg Med 25: 283-287. [Crossref]

43. Yamaguchi S, Ikejima M, Furukawa A, Abe M, Nakazaki M, et al. (2015) Octreotide for hypoglycemia caused by sulfonylurea and DPP-4 inhibitor. Diabetes Res Clin Pract109: e8-10. [Crossref]

44. Umpierrez GE, Hellman R, Korytkowski MT, Kosiborod M, Maynard GA, et al. (2012) Management of hyperglycemia in hospitalized patients in non-critical care setting: an endocrine society clinical practice guideline. J Clin Endocrinol Metab 97: 16-38. [Crossref]

45. Uzzan B, Bentata M, Campos J, Mosnier A, Krivitzky A, et al. (1995) Effects of aerosolized pentamidine on glucose homeostasis, and insulin secretion in HIV-positive patients: a controlled study. AIDS 9: 901-908. [Crossref]

46. Assan R, Perronne C, Assan D, Chotard L, Mayaud C, et al. (1995) Pentamidineinduced derangements of glucose homeostasis: determinant roles of renal failure and drug accumulation: a study of 128 patients. Diabetes Care 18: 47-55. [Crossref]

47. O’brien JG, Dong BJ, Coleman RL, Gee L, Balano KB (1997) A 5-year retrospective review of adverse drug reactions and their risk factors in human immunodeficiency virus - infected patients who were receiving intravenous pentamidine therapy for Pneumocystis carinii pneumonia. Clin Infect Dis 24: 854-859. [Crossref]

48. Saï P, Boillot D, Boitard C, Debray-Sachs M, Reach G, et al. (1983) Pentamidine, a new diabetogenic drug in laboratory rodents. Diabetologia 25: 418-423. [Crossref]

49. Boillot D, Veld PI, Sai P, Feutren G, Gepts W, et al. (1985) Functional and morphological modifications induced in rat islets by pentamidine and other diamidines in vitro. Diabetologia 28: 359-364. [Crossref]

50. Zhou DB, Ipp E (1989) Pentamidine-induced beta cell toxicity is not preventable by high glucose. Am J Med Sci 298: 89-92. [Crossref]

51. Murray M, Lumpkin MD (1997) FDA Public Health Advisory: reports of diabetes and hyperglycemia in patients receiving protease inhibitors for the treatment of human immunodeficiency virus (HIV). Food and Drug Administration, Bethesda (MD).

52. Palma-Aguirre A, Halabe-Cherem J, Nellen-Hummel H, Aburto-Meji'a E, IbarraHerrera E, et al. (2000) Protease inhibitor-associated hyperglycemia in Mexican patients with HIV infection. Arch Med Res 31: 81-84. [Crossref]

53. Behrens G, Dejam A, Schmidt H, Balks HJ, Brabant G, et al. (1999) Impaired glucose tolerance, beta cell function and lipid metabolism in HIV patients under treatment with protease inhibitors. AIDS 13: F63-70. [Crossref]

54. Savès M, François R, Jacqueline C, Rozenbaum W, Ragnaud JM, et al. (2002) Factors related to lipodystrophy and metabolic alterations in patients with human immunodeficiency virus infection receiving highly active antiretroviral therapy. Clin Infect Dis 34: 1396-1405. [Crossref]

55. https://aidsinfo.nih.gov/contentfiles/lvguidelines/adultandadolescentgl.pdf

56. Botella JI, Valero MA, Munoz V, Hurtado A, Varela C (2000) Complete resolution of protease inhibitor induced diabetes mellitus. Clin Endocrinol (Oxf) 52: 241-243. [Crossref]

57. Schambelan M, Benson CA, Carr A, Currier JS, Dubé MP, et al (2002) Management of metabolic complications associated with antiretroviral therapy for HIV-1 infection: recommendations of an International AIDS Society-USA panel. J Acquir Immune Defic Syndr 31: 257-275. [Crossref]

58. https://www.fda.gov/drugs/DrugSafety/ucm293101.htm

59. Rajpathak SN1, Kumbhani DJ, Crandall J, Barzilai N, Alderman M, et al. (2009) Statin therapy and risk of developing type 2 diabetes: a meta-analysis. Diabetes Care 32: 1924-1929. [Crossref]

60. Navarese EP, Buffon A, Andreotti F, Kozinski M, Welton N, et al. (2013) Meta-analysis of impact of different types and doses of statins on new-onset diabetes mellitus. $\mathrm{Am} \mathrm{J}$ Cardiol 111: 1123-1130. [Crossref]

61. Yusuf S, Bosch J, Dagenais G, Zhu J, Xavier D, et al. (2016) Cholesterol lowering in intermediate-risk persons without cardiovascular disease. $N$ Engl J Med 374: 2021 2031. [Crossref]

62. Jones M, Tett S, Peeters GM, Mishra GD, Dobson A (2017) New-Onset Diabetes After Statin Exposure in Elderly Women: The Australian Longitudinal Study on Women's Health. Drugs Aging 34: 203-209. [Crossref]

63. Sukhija R, Prayaga S, Marashdeh M, Bursac Z, Kakar P, et al. (2009) Effect of statins 
on fasting plasma glucose in diabetic and nondiabetic patients. J Investig Med 57: 495499. [Crossref]

64. Ganda OP (2016) Statin-induced diabetes: incidence, mechanisms, and implications. F1000Res 5. [Crossref]

65. Nakata M, Nagasaka S, Kusaka I, Matsuoka H, Ishibashi S, et al. (2006) Effects of statins on the adipocyte maturation and expression of glucose transporter 4 (SLC2A4): implications in glycaemic control. Diabetologia 49: 1881-1892. [Crossref]

66. Abel ED, Peroni O, Kim JK, Kim YB, Boss O, et al. (2001) Adipose-selective targeting of the GLUT4 gene impairs insulin action in muscle and liver. Nature 409: 729-733. [Crossref]

67. Carter BL1, Einhorn PT, Brands M, He J, Cutler JA, et al. (2008) Thiazide-induced dysglycemia: call for research from a working group from the national heart, lung, and blood institute. Hypertension 52: 30-36. [Crossref]

68. Barzilay JI, Davis BR, Cutler JA, Pressel SL, Whelton PK, et al. (2006) Fasting glucose levels and incident diabetes mellitus in older nondiabetic adults randomized to receive 3 different classes of antihypertensive treatment: a report from the Antihypertensive and Lipid-Lowering Treatment to Prevent Heart Attack Trial (ALLHAT). Arch Intern Med 166: 2191-201. [Crossref]

69. Taylor EN, Curhan GC (2006) Antihypertensive medications and the risk of incident type 2 diabetes. Diabetes Care 29: 2334-2335. [Crossref]

70. Shafi T, Appel LJ, Miller ER 3rd, Klag MJ, Parekh RS (2008) Changes in serum potassium mediate thiazide-induced diabetes. Hypertension 52: 1022-1029. [Crossref]

71. Smith SM, Anderson SD, Wen S, Gong Y, Turner ST, et al. (2009) Lack of correlation between thiazide-induced hyperglycemia and hypokalemia: subgroup analysis of results from the pharmacogenomic evaluation of antihypertensive responses (PEAR) study. Pharmacotherapy 29: 1157. [Crossref]

72. Mandal AK, Hiebert LM (2012) Is Diuretic-Induced Hyperglycemia Reversible and Inconsequential? Journal of Diabetes Research and Clinical Metabolism 1: 4

73. Carter BL (2008) Preventing Thiazide-Induced Hyperglycemia: Opportunities for Clinical Pharmacists. Pharmacotherapy 28: 1425-1428. [Crossref]

74. Montori VM, Basu A, Erwin PJ, Velosa JA, Gabriel SE, et al. (2002) Posttransplantation diabetes: a systematic review of the literature. Diabetes Care 25: 583-592. [Crossref]

75. Han E, Kim MS, Kim YS, Kang ES (2016) Risk assessment and management of posttransplant diabetes mellitus. Metabolism 65: 1559-1569. [Crossref]

76. Werner KT, Mackey PA, Castro JC, Carey EJ, Chakkera HA, et al. (2016) Hyperglycemia during the immediate period following liver transplantation. Future Science OA 2: FSO97. [Crossref]

77. Chakkera HA, Weil EJ, Castro J, Heilman RL, Reddy KS, et al. (2009) Hyperglycemia during the immediate period after kidney transplantation. Clin J Am Soc Nephrol 4: 853-859. [Crossref]

78. Davidson J, Wilkinson A, Dantal J, Dotta F, Haller H, et al. (2003) New-onset Diabetes After Transplantation: 2003: International Consensus Guidelines 1. Transplantation 75: 3-24. [Crossref]

79. Weir MR, Fink JC (1999) Risk for posttransplant diabetes mellitus with current immunosuppressive medications. Am J Kidney Dis 34: 1-3. [Crossref]

80. Tamez-Pérez HE, Quintanilla-Flores DL, Rodríguez-Gutiérrez R, González-González JG, Tamez-Peña AL (2015) Steroid hyperglycemia: Prevalence, early detection and therapeutic recommendations: A narrative review. World J Diabetes 6: 1073. [Crossref]

81. Oyer DS, Shah A, Bettenhausen S (2006) How to manage steroid diabetes in the patient with cancer. J Support Oncol 4: 479-483. [Crossref]

82. Øzbay LA, Smidt K, Mortensen DM, Carstens J, Jørgensen KA, et al. (2011) Cyclosporin and tacrolimus impair insulin secretion and transcriptional regulation in INS-1E beta-cells. Br J Pharmacol 162: 136-146. [Crossref]

83. Vincenti F, Tuncer M, Castagneto M, Klinger M, Friman S, et al. (2005) Prospective, multicenter, randomized trial to compare incidence of new-onset diabetes mellitus and glucose metabolism in patients receiving cyclosporine microemulsion versus tacrolimus after de novo kidney transplantation. Transplant Proc 37: 1001-1004. [Crossref]

84. Maes BD, Kuypers D, Messiaen T, Evenepoel P, Mathieu C, et al. (2001) Posttransplantation diabetes mellitus in FK-506-treated renal transplant recipients: analysis of incidence and risk factors. Transplantation 72: 1655-1661. [Crossref]

85. Penfornis A, Kury-Paulin S (2006) Immunosuppressive drug-induced diabetes. Diabetes Metab 32: 539-546. [Crossref]
86. Montori VM, Basu A, Erwin PJ, Velosa JA, Gabriel SE, et al. (2002) Posttransplantation diabetes: a systematic review of the literature. Diabetes Care 25: 583-592. [Crossref]

87. Van Duijnhoven EM, Boots JM, Christiaans MH, Van Hooff JP (2003) Metabolic aspects of tacrolimus in renal transplantation. Consequences for the choice of an immunosuppressive regimen and for the management of post-transplant diabetes mellitus. Minerva urologica e nefrologica. The Italian journal of urology and nephrology 55: 33-42.

88. Kwon S, Hermayer KL (2013) Glucocorticoid-induced hyperglycemia. Am J Med Sci 345: 274-277. [Crossref]

89. Teutonico A, Schena PF, Di Paolo S (2005) Glucose metabolism in renal transplant recipients: effect of calcineurin inhibitor withdrawal and conversion to sirolimus. $J \mathrm{Am}$ Soc Nephrol 16: 3128-3135. [Crossref]

90. Clore JN, Thurby-Hay L (2009) Glucocorticoid-induced hyperglycemia. Endocr Pract 15: 469-474. [Crossref]

91. Trence DL (2003) Management of patients on chronic glucocorticoid therapy: an endocrine perspective. Prim Care 30: 593-605. [Crossref]

92. Donihi AC, Raval D, Saul M, Korytkowski MT, DeVita MA (2006) Prevalence and predictors of corticosteroid-related hyperglycemia in hospitalized patients. Endocr Pract 12: 358-362. [Crossref]

93. Low Wang CC, Draznin B (2016) use of NPH Insulin for glucocorticoid-induced hyperglycemia. Endocr Pract 22: 271-273. [Crossref]

94. Perez A, Jansen-Chaparro S, Saigi I, Bernal-Lopez MR, Miñambres I, et al. (2014) Glucocorticoid-induced hyperglycemia. J Diabetes 6: 9-20. [Crossref]

95. Van Raalte DH, Ouwens DM, Diamant M (2009) Novel insights into glucocorticoidmediated diabetogenic effects: towards expansion of therapeutic options? Eur J Clin Invest 39: 81-93. [Crossref]

96. Ruzzin J, Wagman AS, Jensen J (2005) Glucocorticoid-induced insulin resistance in skeletal muscles: defects in insulin signalling and the effects of a selective glycogen synthase kinase-3 inhibitor. Diabetologia 48: 2119-2130. [Crossref]

97. American Diabetes Association (2016) 13. Diabetes care in the hospital. Diabetes Care 39: 99-104. [Crossref]

98. Van Raalte DH, Van Genugten RE, Linssen MM, Ouwens DM, Diamant M (2011) Glucagon-like peptide-1 receptor agonist treatment prevents glucocorticoid-induced glucose intolerance and islet-cell dysfunction in humans. Diabetes Care 34: 412-417. [Crossref]

99. Action to Control Cardiovascular Risk in Diabetes Study Group, Gerstein HC, Mille ME, Byington RP, Goff DC Jr, et al. (2008) Effects of intensive glucose lowering in type 2 diabetes. $N$ Engl J Med 358: 2545-2559. [Crossref]

100. ADVANCE Collaborative Group, Patel A, MacMahon S, Chalmers J, Neal B, et al. (2008) Intensive blood glucose control and vascular outcomes in patients with type 2 diabetes. N Engl J Med 358: 2560-2572. [Crossref]

101. Murad MH, Coto-Yglesias F, Wang AT, Sheidaee N, Mullan RJ, et al. (2009) Drug induced hypoglycemia: a systematic review. J Clin Endocrinol Metab 94: 741-745. [Crossref]

102. Lee AJ, Maddix DS (1997) Trimethoprim/sulfamethoxazole-induced hypoglycemia in a patient with acute renal failure. Ann Pharmacother 31:727-732. [Crossref]

103. Bell DS (2004) Advantages of a third-generation $\beta$-blocker in patients with diabetes mellitus. Am J Cardiol 93: 49-52. [Crossref]

104. Mathews WA, Manint JE, Kleiss J (2000) Trimethoprim-sulfamethoxazole-induced hypoglycemia as a cause of altered mental status in an elderly patient. $J$ Am Board Fam Pract 3: 211-212. [Crossref]

105. Aspinall SL, Good CB, Jiang R, McCarren M, Dong D, et al. (2009) Severe dysglycemia with the fluoroquinolones: a class effect? Clin Infect Dis 49: 402-408. [Crossref]

106. Kelesidis T, Canseco E (2009) Levofloxacin-induced hypoglycemia: a rare but lifethreatening side effect of a widely used antibiotic. Am J Med 122: e3-4. [Crossref]

107. Chou HW, Wang JL, Chang CH, Lee JJ, Shau WY, et al. (2013) Risk of severe dysglycemia among diabetic patients receiving levofloxacin, ciprofloxacin, or moxifloxacin in Taiwan. Clin Infect Dis 57: 971-980. [Crossref]

108. Wang S, Rizvi AA (2006) Levofloxacin-induced hypoglycemia in a nondiabetic patient. Am J Med Sci 331: 334-335. [Crossref]

109. Khovidhunkit W, Sunthornyothin S (2004) Hypoglycemia, hyperglycemia, and 
gatifloxacin. Ann Intern Med 141: 969. [Crossref]

110. Ghaly H, Kriete C, Sahin S, Pflöger A, Holzgrabe U, et al. (2009) The insulinotropic effect of fluoroquinolones. Biochem Pharmacol 77: 1040-1052. [Crossref]

111. Sattler FR, Cowan R, Nielsen DM, Ruskin J (1998) Trimethoprim-Sulfamethoxazole Compared with Pentamidine for Treatment of Pneumocystis carinii Pneumonia in the Acquired Immunodeficiency SyndromeA Prospective, Noncrossover Study. Ann Intern Med 109: 280-287. [Crossref]
112. Spadafora MP, Roberts JR (1986) Hypoglycemic coma from pentamadine in an AIDS patient. Am J Emerg Med 4: 384. [Crossref]

113. Phillips RE, Looareesuwan S, White NJ, Chanthavanich P, Karbwang J, et al. (1986) Hypoglycaemia and antimalarial drugs: quinidine and release of insulin. $\mathrm{Br} \mathrm{Med} \mathrm{J}$ (Clin Res Ed) 292: 1319-1321. [Crossref]

114. Looareesuwan S, Phillips RE, White NJ, Kietinun S, Karbwang J, et al. (1985) Quinine and severe falciparum malaria in late pregnancy. Lancet 2: 4-8. [Crossref]

Copyright: $\odot 2017$ Korayem GB. This is an open-access article distributed under the terms of the Creative Commons Attribution License, which permits unrestricted use, distribution, and reproduction in any medium, provided the original author and source are credited. 